https://doi.org/10.29296/25877305-2018-12-19

Локальная импульсная

\title{
магнитотерапия
}

\section{аппаратом «АЛМАГ+»}

\section{в комплексном лечении}

\section{больных остеоартрозом}

Ю. Бяловский ${ }^{1}$, доктор медицинских наук, профрессор,

\section{А. Иванов²,}

Н. Ларинский ${ }^{3}$, кандидат медицинских наук,

\section{А. Секирин ${ }^{4}$}

${ }^{1}$ Рязанский государственный медицинский университет

20АО «Елатомский приборный завод»,

Елатьма, Рязанская область

${ }^{3} 000$ «Санаторий Солотча», Рязань

${ }^{4}$ МОНИКИ им. М.Ф. Владимирского, Москва

E-mail: b_uu@mail.ru

Изучена эфффективность локальной импульсной магнитотерапии аппаратом «АЛМАГ+» в комплексной терапии больных остеоартрозом.

Ключевые слова: терапия, остеоартроз, импульсная магнитотерапия, болевой синдром.

Для цитирования: Бяловский Ю., Иванов А., Ларинский Н. и др. Локальная импульсная магнитотерапия аппаратом «АЛМАГ+» в комплексном лечении больных остеоартрозом // Врач. - 2018; 29 (12): 75-79. https://doi. org/10.29296/25877305-2018-12-19

\section{АКТУАЛЬНОСТЬ ПРОБЛЕМЫ}

стеоартроз (ОА) занимает ведущее положение среди костно-суставных заболеваний, встречаясь у 6,5-12\% больных ортопедического профиля и составляя $>50 \%$ всех ревматических болезней [1-3]. Социальное значение проблемы ОА определяется ущербом, который причиняет временная и стойкая утрата трудоспособности, лишающая больных возможности активной профессиональной деятельности, а также ухудшением качества жизни в связи с ограничением двигательной активности. Только за последние десятилетия нетрудоспособность из-за этого заболевания увеличилась в 3-5 раз [4-6].

При ОА нарушаются окислительно-восстановительные процессы. В тканях выявляют выраженную гипоксию со значительным расстройством окислительно-восстановительных процессов, что проявляется снижением дыхательной способности клеток, т.е. ингибированием ферментных систем [7-9].

Фактором, дающим сосудорасширяющий, метаболический, противоотечный, гипокоагулирующий, 
гипотензивный, трофостимулирующий и гипоальгезивный эффекты, является магнитное поле (МП) $[10,11]$. В последние годы получены убедительные доказательства успешного использования магнитотерапии в составе комплексного лечения ОА, показаны значимое уменьшение при этом боли и функциональных нарушений суставов, безопасность и эффективность магнитотерапии [12, 13].

В последние годы весьма распространенным стало использование импульсной магнитотерапии. Варьируя параметры МП и локализацию его воздействия при импульсной магнитотерапии, можно получить самые разные физиологические и терапевтические эффекты: местный обезболивающий, миостимулирующий, нейростимулирующий. Импульсные МП (ИМП), вызывая усиление локального кровотока на стадии стихания острого процесса и реконвалесценции, способствуют удалению продуктов аутолиза из очага воспаления и ослаблению воспалительной реакции. Улучшение микроциркуляции стимулирует регенераторные процессы в поврежденных тканях и улучшает их трофику. Получены убедительные основания считать, что по степени выраженности стимулирующего, обезболивающего и противовоспалительного действия импульсная магнитотерапия многократно превосходит все известные виды низкоинтенсивной магнитотерапии [14-16].

Известна выраженная зависимость регионального кровообрашения и коагуляционных свойств крови от состояния неспецифических адаптационных механизмов, которые определяются активностью 2 взаимосвязанных систем-антагонистов: стресслимитирующей и стресс-реализующей [17]. В ряде работ доказано влияние ИМП на изменение состояния неспецифических адаптационных механизмов путем активации стресс-реализующей или стресслимитирующей систем $[18,19]$. Это значит, что применение ИМП определенных параметров позволяет влиять на качество лечения ОА. Однако в литературе мы не обнаружили работ, посвященных оценке эффективности импульсной магнитотерапии OA c учетом направленности неспецифических адаптационных механизмов.

В связи с этим представлялось целесообразным изучить влияние локального применения импульсной магнитотерапии на избирательную активацию стрессреализующих систем и оценить эффективность бегущего ИМП (БИМП) от аппарата «АЛМАГ+» в составе комплексной терапии больных ОА.

Целью исследования было оценить эффективность БИМП от аппарата «АЛМАГ+» в составе комплексной терапии больных ОА.

\section{МАТЕРИАЛ И МЕТОДЫ}

В основную группу и группу сравнения включали больных ОА коленного сустава - КС (гонартроз) I-III стадий в соответствии с кассификацией I. Kellgren, I. Lawrence.

Пациенты основной группы получали лечение ИМП («АЛМАГ+», регистрационное удостоверение №Р3Н 2017/6194 от 23.11.17, на курс лечения - 15 процедур с кратностью: 1 процедура в день) и нестероидными противовоспалительными препаратами - НПВП (диклофенак - 25 мг 3 раза в сутки). Использовался I (основной) режим магнитотерапии аппаратом «АЛМАГ+». Применяли излучатели в виде гибкой линейки из 4 индукторов, накладываемых на поясничнокрестцовую область стороной $\mathrm{N}$ к телу. Время воздействия - 15 мин. Пациенты группы сравнения получали только НПВП (диклофенак - 25 мг 3 раза в сутки, курс - 15 дней).

По завершении курса лечения осуществлялось динамическое наблюдение больных. Через 3 и 6 мес с момента выписки проводилось клиническое, лабораторное и инструментальное обследование.

Функциональное состояние пораженных суставов оценивали по суставным индексам Лекена, Ли, Ричи, Заболотных, выраженность болевого синдрома по визуальной аналоговой шкале (ВАШ) боли 10-сантиметровая шкала, на которой пациенты отмечали выраженность боли: от 0 до 10 - при ее максимальной выраженности.

Для оценки степени нарушения функции суставов использовали критерии медицинской экспертизы при деформирующих артрозах [9]. Всем больным для верификации диагноза ОА делали рентгеновский снимок проблемного сустава. Рентгенологическую стадию ОА определяли по класификации I. Kellgren, I. Lawrence в модификации M. Lequesne.

В основную группу (БИМП + НПВП) входили 25 пациентов от 36 до 65 лет с ОА. В возрасте до 40 лет было 2 (8\%) больных, от 40 до 50 лет - 7 (28\%), от 51 до $60-9$ (36\%), старше 60 лет - 3 (12\%); средний возраст пациентов - 50,6 $\pm 8,4$ года. В $22(88 \%)$ случаях был поставлен диагноз полиостеоартроза; у 18 больных диагностирована узелковая форма ОА, у 4 - безузелковая, у 3 - олигоартроз узелковой формы, безузелковый олигоартроз - у 3 (12\%) больных. І рентгенологическая стадия определена у 4 (16\%) пациентов, II - у 15 (60\%), III - у 6 (24\%). Синовит КС определялся у 5 (20\%) больных. В основной группе 3 (75\%) больных ОА I рентгенологической стадии имели давность заболевания от 1 года до 5 лет, 1 (25\%) больной - 7 лет; средняя продолжительность заболевания составила 4,3 1 , 9 года. У больных ОА II рентгенологической стадии давность заболевания составила 1 год у $1(6,6 \%)$ больного, от 1 года до 5 лет - у 7 (46,6\%), 6 лет - у $2(13,3 \%)$ и 10 лет у $5(33,3 \%)$; средняя продолжительность заболевания составила $7,8 \pm 2,5$ года. При ОА ІІІ рентгенологической стадии 2 больных имели продолжительность страдания 5 лет, 1 (16\%) - 9 лет и $3(50 \%)->10$ лет; средняя продолжительность болезни - 12,7 $\pm 3,2$ года. 
В группу сравнения $(\mathrm{n}=25)$ вошли больные, получавшие только НПВП. Средний возраст больных

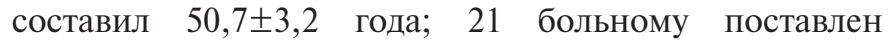
диагноз полиостеоартроза, 15 - ОА узелковой формы, 6 - безузелковой. ОА I рентгенологической стадии страдали 5 (20\%) больных, II стадии - 14 (56\%), III 6 (24\%). У 17 (68\%) больных выявлен синовит КС. Средняя продолжительность заболевания при ОА I рентгенологической стадии составила $6,9 \pm 4,1$ года, у $3(60 \%)$ пациентов - от 1 до 5 лет и у $2(40 \%)-$ от 5 до 8 лет. Из 14 больных ОА ІІ рентгенологической стадии 8 (57\%) имели продолжительность болезни $<1$ года, $3(21 \%)-1-5$ лет и $3(21 \%)->10$ лет; средняя продолжительность заболевания у этих больных составила

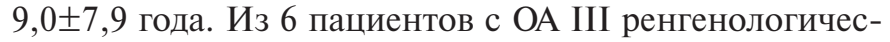
кой стадии $4(66,6 \%)$ имели продолжительность заболевания 5 лет, 2 (33,3\%) - 12 лет; средняя продол-

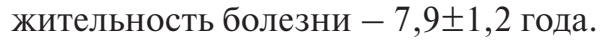

Результаты обрабатывали методом вариационной статистики. Вычисляли среднее значение признака, стандартное отклонение, стандартную ошибку. Использовали критерий Стьюдента с последующим определением уровня достоверности различий (p).

\section{РЕЗУЛЬТАТЫ И ОБСУЖДЕНИЕ}

В группе сравнения наибольший клинический эффект выявлен у больных ОА I рентгенологической стадии (рис. 1). У них снижались суставной индекс Ричи, показатели ВАШ и функциональный индекс Лекена $(\mathrm{p}<0,05)$. При ОА II ренгенологической стадии отмечены достоверное снижение боли по ВАШ, индексов Лекена и Ли $(\mathrm{p}<0,05)$. У пациентов группы сравнения с III рентгенологической стадией оцениваемые индексы изменялись недостоверно. Индекс Заболотных, оценивающий интенсивность парестезий, при всех рентгенологических стадиях имел незначительную тенденцию к уменьшению. Наблюдалось отсутствие клинической эффективности после приема диклофенака у 4 (16\%) пациентов: у 2 со II рентгенологической стадией ОА и у 2 - с III. При наблюдении в динамике у большинства больных, особенно с II и III рентгенологическими стадиями, отмечено возобновление жалоб на боли; появление проблем при движениях произошло через 2 нед с момента окончания курсового лечения НПВП. У пациентов, имеющих синовит, болевой синдром прежней интенсивности возобновлялся на 3-й день после окончания курса лече-

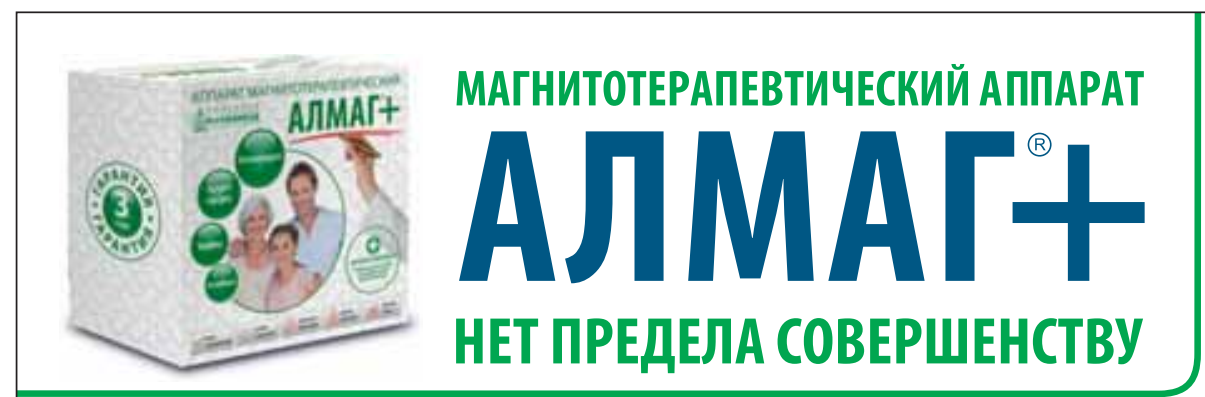

Аппарат предназначен для физиотерапевтического лечения и проведения восстановительно-реабилитационных мероприятий низкочастотным низкоинтенсивным бегущим и неподвижным импульсным магнитным полем в условиях лечебных, лечебно-профилактических учреждений, а также в домашних условиях по рекомендацииврача.

\section{По сравнению с АЛМАГОМ-01 в аппарате «АЛМАГ+» реализованы:}

1. Три режима работы:

$\checkmark$ Классический режим. Частота 6,25Гц и интенсивность 20 мТл

$\checkmark$ Режим с выраженным обезболивающим и противовоспалительным эффектами. Частота 100Гц и интенсивность 6 мТл

$\checkmark$ Режим для педиатрии. Частота 6,25Гц и интенсивность 8 мТл

2. Возможность трансформации излучателей в линейку (1х4) и матрицу (2×2), позволяющая воздействовать на парные органы и одновременно на симметричные участки тела.

3. Звуковая индикация

4. Возможность фиксации на теле пациента за счет Конструктивных элементов на индукторах .

5. Таймер воздействия под каждую программу

6. Два вида магнитных полей, генерируемых аппаратом:

$\checkmark$ «бегущее», при котором происходит последовательное возбуждение всех катушекиндукторов;

$\checkmark$ «неподвижное», при котором происходит одновременное возбуждение всех катушекиндукторов.

\section{Показания к применению:}

$\checkmark$ поражения отдельных нервных корешков и сплетений верхних и нижних конечностей, в том числе после травм, перенесенного инсульта;

$\checkmark$ болезни вен и лимфатических сосудов (включая варикозную болезнь и ее осложнения, лимфостаз);

$\checkmark$ дорсопатия (остеохондроз позвоночника, грыжа межпозвоночного диска, сколиоз);

$\checkmark$ артриты, артрозы, остеохондропатии, пяточная шпора;

$\checkmark$ осложнения сахарного диабета I и II типа;

$\checkmark$ дистония (вегетососудистая дистония);

$\checkmark$ гипертоническая болезнь I, II степени;

$\checkmark$ травмы (переломы);

$\checkmark$ бронхиальная астма;

$\checkmark$ атеросклероз;

$\checkmark$ остеопороз;

$\checkmark$ бронхит;

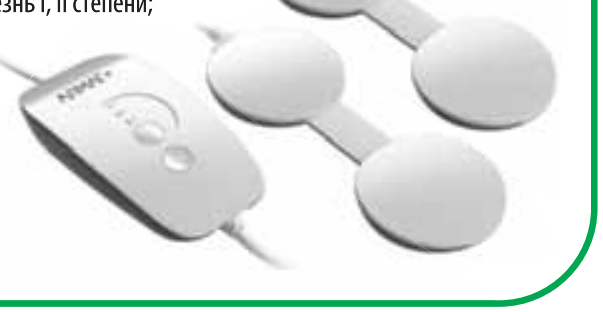


ния; лишь у 4 (23,5\%) больных с ОА I рентгенологической стадии достигнутый эффект сохранялся на протяжении 2 нед. Динамическое наблюдение пациентов с I и II рентгенологическими стадиями ОА группы сравнения через 3 мес выявило достоверное усиление боли и нарушение функции суставов, а к 6-му месяцу болевые ощущения возвращались к первоначальным значениям. Интенсивность парестезий через 0,5 года после окончания лечения имела тенденцию к повышению. У пациентов с III рентгенологической стадией уже к 3-му месяцу все суставные индексы возвращались к первоначальным значениям. Таким образом, выявленная в ходе монотерапии НПВП пациентов с OA положительная динамика функциональных индексов и индекса боли устойчиво сохраняется в срок до 2 нед. Через 3 мес после курса лечения интенсивность боли и нарушение функции возвращались к исходному уровню.

В основной группе (БИМП + НПВП) больные ОА I рентгенологической стадии отметили уменьшение боли и скованности в суставах в первые 3 дня от начала

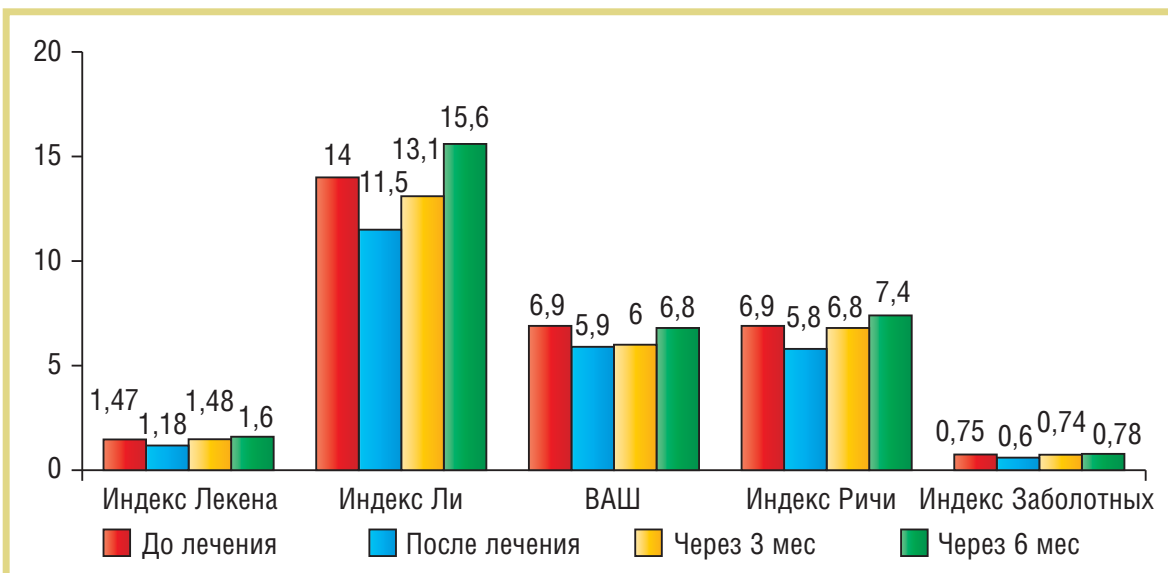

Рис. 1. Оценка функционального состояния больных ОА группы сравнения с применением тестов Ричи, Лекена, Ли, ВАШ, Заболотных при монотерапии НПВП

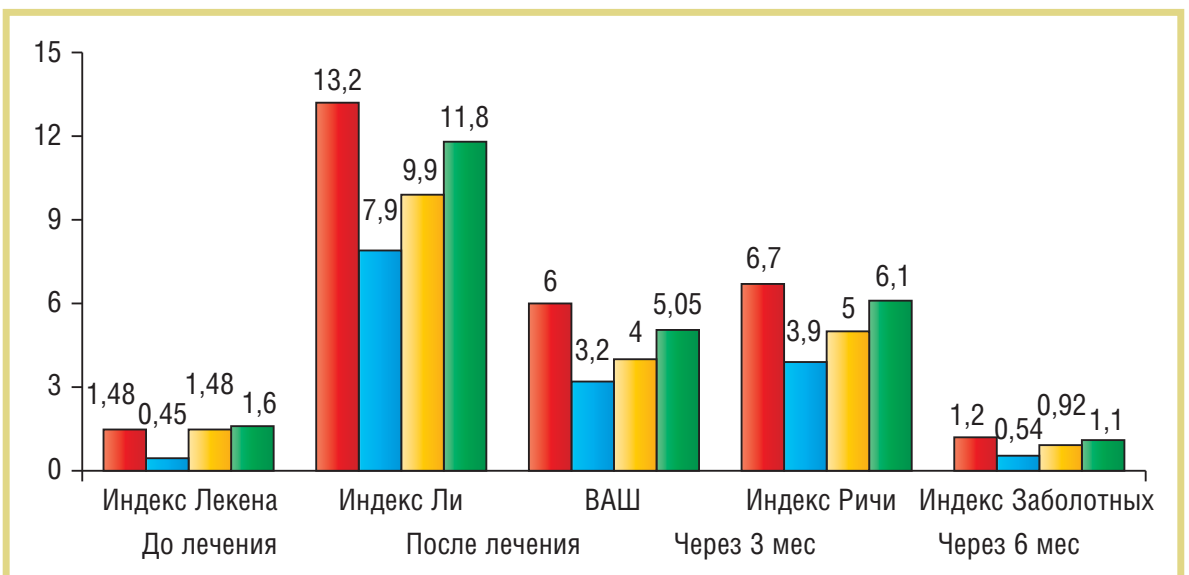

Рис. 2. Оценка функционального состояния больных ОА с применением тестов Ричи, Лекена, Ли, ВАШ, Заболотных при комбинированной терапии НПВП и БИМП с помощью «АЛМАГ+» лечения; 7 (46,6\%) больных ОА II рентгенологической стадии зафиксировали указанные изменения в первые 4 дня, 5 (33,3\%) - в первые 4-8 дней, 3 (20\%) - позже 8 -го дня. Улучшение в первые 4 дня отмечено только у $1(16,6 \%)$ больного ОА III рентгенологической стадии, в срок от 4 до 8 дней - у 3 (50\%), позже 8-го дня от начала лечения - у 1 (16,6\%). Положительный эффект у больных ОА I рентгенологической стадии отмечался в среднем на 4-й день от начала лечения, при II рентгенологической стадии - на 5-й день; при III стадии - на 6-7-й день. После окончания курса лечения у больных ОА I и II рентгенологических стадий отмечены положительная динамика болевого синдрома (по Ричи) и оценки боли по ВАШ, уменьшение парестезий (по индексу Заболотных) и улучшение функции суставов (по Лекену и Ли; $p<0,005 ;$ рис. 2). У больных этой группы с ОА III рентгенологической стадии наблюдались достоверное улучшение функции суставов, существенное снижение боли по ВАШ, а интенсивность боли по артикуляционному индексу Ричи и выраженность сосудистых расстройств снижались статистически недостоверно (p>0,05). У 1 больного ОА III рентгенологической стадии лечение не дало эффекта. При изучении катамнеза обнаружилось, что спустя 3 мес у больных ОА I рентгенологической стадии положительные изменения сохранялись, а через 6 мес появилась тенденция к увеличению интенсивности болевого синдрома и нарушениям функций сустава. У больных ОА II рентгенологической стадии спустя 3 мес усилились болевой синдром и выраженность парастезии, что достоверно показали индекс Ричи, Заболотных и шкала ВАШ. При этом аналогичного ухудшения функции суставов по Лекену и Ли не наблюдалось. Через 6 мес отмечено достоверное повышение выраженности болевого синдрома, парастезий и нарушений функции сустава, но эти симптомы не достигали уровня исходных значений.

Таким образом, у пациентов основной группы с I-II рентгенологической стадиями ОА, получавших комплексную терапию (БИМП + НПВП), отмечены снижение выраженности болевого синдрома, улучшение функции суставов, что характеризует достижение устойчивой ремиссии. Только у пациентов c OA III рентгенологической стадии положительная динамика была выражена меньше. 
Через 6 мес при I рентгенологической стадии отмечено сохранение клинического улучшения, при II рентгенологической стадии наблюдалась тенденция к ухудшению, ноинтенсивностьсимптомовбылавыражена меньше, чем исходно. При ОА ІІІ рентгенологической стадии болевой синдром и нарушения функции возвращались к исходной интенсивности.

Таким образом, при анализе динамики исследованных показателей у пациентов, получавших комплексную терапию - БИМП и НПВП (диклофенак), отмечены уменьшение болевого синдрома и улучшение функции суставов и только у больных с III рентгенологической стадией изменения этих параметров носили менее выраженный характер. Наиболее продолжительное клиническое улучшение - 6 мес - сохранялось у пациентов с I рентгенологической стадией; при II рентгенологической стадии через 3 мес наблюдался регресс симптомов, а через 6 мес - их достоверное усиление, хотя интенсивностьсимптомовбылавыражена меньше, чем исходно. При ОА III рентгенологической стадии уровень боли и нарушения функций увеличивались к 3-му месяцу до исходного уровня.

Исследование показало, что:

- наблюдавшиеся на фоне монотерапии НПВП клинические эффекты (снижение суставного индекса Ричи, ВАШ и функционального индекса Лекена) сохранялись недолго (до 2 нед); ремиссия наблюдалась преимущественно у больных ОА I-II рентгенологических стадий;

- у большинства больных ОА, особенно с II и III рентгенологическими стадиями, на фоне монотерапии НПВП возобновление жалоб на боли, появление проблем при движениях произошло через 2 нед с момента окончания курсового лечения НПВП;

- у пациентов с синовитом и получавших монотерапию НПВП болевой синдром прежней интенсивности возобновлялся на 3-й день после окончания курса лечения;

- в основной группе (БИМП + НПВП) практически все больные ОА отметили уменьшение боли и скованности, наблюдались достоверно положительная динамика степени болевого синдрома (по Ричи) и оценки боли по ВАШ, уменьшение парестезий (по индексу Заболотных) и улучшение функции суставов (по Лекену и Ли);

- при динамическом наблюдении пациентов, получавших комплексную терапию (БИМП + НПВП), через 3 мес выявлено достоверное улучшение функции суставов, существенное снижение боли по ВАШ, а интенсивность боли по артикуляционному индексу Ричи снижалась статистически недостоверно; наиболее продолжительная ремиссия 6 мес - сохранялась у пациентов, получавших комплексную терапию (БИМП + НПВП).

\section{Литература}

1. Пайл К., Кеннеди Л. Диагностика и лечение в ревматологии. Проблемный подход. Пер с англ. / М.: ГЭОТАР-Медиа, 2011; 368 с.

2. Ортопедия: национальное руководство. Под ред. С.П. Миронова, Г.П. Котельникова. 2-е изд., перераб. и доп. / М.: ГЭОТАР-медиа, 2013; $944 \mathrm{c}$.

3. Насонова В.А. Международная декада, посвященная костносуставным нарушениям // Рус. мед. журн. - 2000; 8 (9): 27-32.

4. Насонов Е.Л., Насонова В.А. Рациональная фрармакотерапия ревматических заболеваний. Руководство для практикующих врачей / М.: «Литтера», 2003; с. 507.

5. Насонов Е.Л., Насонова В.А., Ревматология: национальное руководство / М.: ГЭОТАР-Медиа, 2008; 720 с.

6. Лялина В.В., Сторожаков Г.И. Грамматика артрита / М.: «Практика», 2010; 168 c.

7. Котельников Г.П. Диагностика и консервативное лечение остеоартроза крупных суставов // Медицинская газета. - 2000; 11: 8-9.

8. Корнилов Н.Н. Современные взгляды на этиопатогенез, принципы диагностики и консервативную терапию дегенеративно-дистросических заболеваний коленного сустава // Травматология и ортопедия России. - 2005; 2: 47-9.

9. Roos E., Roos H., Lohmander L. et al. Knee Injury and osteoarthritis Outcome Score (KOOS) - development of a self-administered outcome measure // J. Orthop. Sports Phys. Ther. - 2007; 28: 88-96.

10. Максимов А.В. Физиотерапия и курортология. Под ред. В.М. Боголюбова. Кн. I / М.: Издательство Бином, 2008; 408 с.

11. Улащик В.С., Лукомский И.В. Общая физиотерапия. Учебник. 3-е изд., стереотип. / Мн.: Книжный Дом, 2008; 512 с.

12. Ушаков А.А. Практическая физиотерапия / М.: МИА, 2009; 608 с.

13. Физическая и реабилитационная медицина: национальное руководство. Под ред. Г.Н. Пономаренко / М.: ГЭОТАР-Медиа, 2016; 688 с.

14. РуденкоЭ.В.,Шалатонина О.И.,УлащикВ.С. идр.Магнитотерапевтический аппарат «Ортоспок»: обоснование использо-вания и лечебное применение / Белорусский центр научной медицинской инсоомации, 2000; 43 c.

15. Демецкий А.М., Чернов В.Н., Попова Л.И. Введение в медицинскую магнитологию / Ростов-на-Дону: Изд-во Рост. ун-та, 1991; 96 с.

16. Григорьева В.Д., Суздалышцкий Д.В., Федорова Н.Е. Новые подходы к применению физических факторов в практике медицинской реабилитации больных остеоартритом // Вопросы курортологии, физиотерапии и лечебной физкультуры. - 2000; 1: 3-7.

17.Бяловский Ю.Ю., Булатецкий С.В., Глушкова Е.П. Системная организа-ция неспецифических механизмов адаптации в восстановительной медицине. Монография / Воронеж, 000 «Издательство РИТМ», 2017; $406 \mathrm{c}$.

18. Булатецкий С.В. Физиологические механизмы успешности профессиональной подготовки курсантов образовательных учреждений МВД России. Авторефр. дис. ... д-ра мед. наук, Рязань, 2008; с.48.

19. Бяловский Ю.Ю., Сучкова Ж.В. Изменения неспецифических адаптационных механизмов в условиях локальных физиотерапевтических воздействий // Клиническая патофизиология. - 2003; 1: 47-52.

\section{LOCAL IMPULSE MAGNETIC THERAPY WITH AN ALMAG+ APPARATUS IN THE COMBINATION TREATMENT OF PATIENTS WITH OSTEOARTHRITIS Professor Yu. Byalovsky', MD; A. Ivanov'; N. Larinsky $^{3}$, Candidate of Medical Sciences; A. Sekirin ${ }^{4}$ \\ ${ }^{1}$ Ryazan State Medical University \\ ${ }^{2} \mathrm{OAO}$ Elatma Instrumental-Making Plant, Elatma, Ryazan Region \\ ${ }^{3} 000$ Solotcha Sanatorium, Ryazan \\ ${ }^{4}$ M.F. Vladimirsky Moscow Regional Clinical Research Institute, Moscow}

The authors have investigated the efficiency of local impulse magnetic therapy using an ALMAG+ apparatus in the combination treatment of patients with osteoarthrosis.

Key words: therapy, osteoarthrosis, impulse magnetic therapy, pain syndrome. For citation: Byalovsky Yu., Ivanov A., Larinsky N. et al. Local impulse magnetic therapy with an ALMAG+ apparatus in the combination treatment of patients with osteoarthritis // Vrach. - 2018; 29 (12): 75-79. https://doi. org/10.29296/25877305-2018-12-19 